East African Journal of Science, Technology and Innovation, Vol. 2 (2), March 2021

This article is licensed under a Creative Commons license, Attribution 4.0 International (CC BY 4.0)

\title{
Impact of agricultural commercialization on household food security among smallholder farmers in Zhombe North Rural District, Zimbabwe
}

1*MADUDUDU P., 2NDAYITWAYEKO W M., 3MWAKIWA E., 4MUTAMBARA J.

1,3,4 Faculty of Agriculture Environment and Food Systems, Department of Agricultural Business Development and Economics. P O Box MP 167 Mount Pleasant, Harare, Zimbabwe

${ }^{2}$ University of Burundi Faculty of Economics and Management B. P. 1550 Bujumbura, Burundi

* Corresponding Author: matarutsepamela@yahoo.com

\begin{abstract}
Agricultural commercialization is one of the proposed strategies to alleviate the problem of food insecurity in Africa. This paper contributes towards the debate on the impact of agricultural commercialization on household food security by assessing the impact of agricultural commercialization on household food security. Cross-sectional data for the 2017/18 farming season was collected from 165 smallholder farmer households in Zhombe North Rural District in Zimbabwe. Propensity score matching model was used for data analysis. Crop output market participation share (COMPS) and crop input market participation share (CIMPS) were jointly used as a proxy of agricultural commercialization of a household. Findings indicated that agricultural commercialization had a positive significant average treatment effect on the treated (ATT) of 5.25 modified food consumption scores on households' food security. The paper recommends the promotion of agricultural commercialization as a strategy to improve household food security.
\end{abstract}

Keywords: Agricultural commercialization; Impact; Food security; Propensity score matching; Smallholder farmers

Cite as: Madududu et al., (2021) Impact of agricultural commercialization on household food security among smallholder farmers in Zhombe North Rural District, Zimbabwe. East African Journal of Science, Technology and Innovation 2(2).
Received: $\quad 21 / 10 / 20$

Accepted: 18/03/21

Published: 25/03/21 


\section{Introduction}

Zimbabwe is one of the countries experiencing serious food insecurity problem in Sub-Saharan Africa, perpetuated by the deteriorating economy evidenced by seemingly to be uncontrollable hyperinflation level, high unemployment rate, and climate change amongst other intertwined reasons (Hall et al., 2017). In Zimbabwe, agriculture plays a big role in economic stability and growth contributing approximately $18 \%$ to the gross domestic product (GDP) (Mapfumo, 2015). However, the country is described as a food-deficit country with a very fragile food security situation (ZIMSTAT, 2017). Seventy percent of Zimbabwean rural households depend primarily on agriculture for their livelihoods (GOZ, 2018). Challenges facing farming households in Zimbabwe include cash shortages and pest attacks (such as fall armyworm) amongst the other environmental and economic problems that are negatively affecting agricultural production (ZimVAC, 2018) According to the World Bank country data, the total percentage of undernourished people in Zimbabwe has been rising (World Bank, 2019). This is partly due to climate change, declining agricultural productivity and unfavourable economic conditions in the country, which reduces the availability and access of food to households (ZimVAC, 2018). In Zimbabwe, 33\% of the population was undernourished in 2016 (ZIMSTAT, 2017). The trends show that Zimbabwe is facing a rise in the undernourished population percentages with a sharp rise mainly experienced from the year 2011.

Economists and politicians acknowledge that agriculture is a driver for growth in Africa with the potential to end poverty and hunger (Timmer, 2005). Agricultural commercialisation is one of the strategies used to raise farm incomes and to achieve overall economic development, however, there lacks clear evidence in terms of its contribution to household food security (Carletto et al., 2017; Radchenko and Corral, 2018). Agricultural commercialisation involves the transformation from producing to satisfy household consumption to producing for the market. As households commercialise, their farming systems pave way for more specialised forms of production meant to respond rapidly to the market phenomena and use of quality inputs (Jaleta et al., 2009). Agricultural commercialisation creates a virtuous cycle through which farmers intensify their use of the productivity-enhancing technologies so that they can achieve a higher level of output hence raising incomes and the standards of the household living (Jayne et al., 2011). Agricultural commercialisation is a combination of market orientation aimed at profit maximisation and market participation aimed at utility maximisation (Jaleta et al., 2009).

The debate over the effects of agricultural commercialisation centres on food security though it is known that farming households' incomes increase through agricultural commercialisation (Radchenko and Corral, 2018). Agricultural commercialisation has the potential to increase access to improved inputs and marketed food hence reducing the food insecurity problem (Radchenko and Corral, 2018; Rukuni, 2002). The food insecurity problem proves to be a major challenge especially in smallholder farmers whose livelihoods depend on rain-fed agriculture (FAO et al., 2018). The situation calls for heightened collaborative interventions and policy reforms with short term, mid-term and long-term scope by specialists, governments and development partners. Food security is defined as a situation whereby "all people at all times, have physical, social and economic access to sufficient, safe and nutritious food to meet their dietary needs and food preferences for an active healthy life" as per FAO 1996 definition.

Agricultural commercialization is one of the strategies used to raise farm incomes and to achieve overall economic development, however, there lacks clear evidence in terms of its contribution to household food security (Carletto et al., 2017; Radchenko and Corral, 2018). The effect of agricultural commercialization on food security and nutrition has been a controversial matter since the 1990s with studies showing weak positive, neutral to negative effects (Carletto et al., 2017; Linderhof et al., 2019). Other scholars point the weak evidence to the improper 
definition of agricultural commercialization that was previously treated as a dichotomous variable through grouping farmers into cash crop adopters and non-cash crop adopters (Carletto et al., 2017; Linderhof et al., 2019).

A most recent study in Vietnam points out that the effect of agricultural commercialization on household food security is heterogeneous (Linderhof et al., 2019). Besides the issue of inconclusive evidence on the subject matter, there are also limited studies that have properly addressed the structural confounding problem in exploring the impact of agricultural commercialization on household food security (Ogutu et al., 2017). A structural confounding problem happens when one needs to compare two groups that have different characteristics. This problem can be resolved by applying the propensity score matching technique.

A commercialized farming household is the one that produces significant amounts of crops for sale and makes use of improved inputs in their production (Strasberg et al., 1999). The researchers defined a commercialized household as the one that purchases agricultural inputs from the market and sells its farm output whilst a noncommercialized household was regarded as the one that does not purchase agricultural inputs and sells farm output. This study uses formula (a) to calculate the Crop Output Market Participation Share (COMPS) and formula (b) to calculate the Crop Input Market Participation Share (CIMPS):

\section{$\operatorname{COMPS}_{i}=$}

Gross value of field crops sold by ith household in year $j$

Gross value of all field crops produced by ith household in year $j$ (a)

$\operatorname{CIMPS}_{i}=$

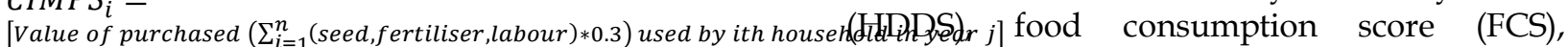
(b) [Gross value of agricultural inputs used by ith household in yedrojusehold food insecurity access scale (HFIAS),

In this regard, the crops which were used by the researchers in determining the COMPS are maize, cotton, groundnuts, sorghum, roundnuts and cowpeas because they are the crops commonly grown in the Zhombe North Rural District. The gross monetary value of these crops was used to calculate the COMPS index. In calculating the CIMPS, value of the purchased inputs which are seed, fertilizer and labour were used.

Given that agricultural commercialization levels occur as proportions that vary from $0 \%$ to $100 \%$, this study grouped households into commercialized and non-commercialized ones basing on their level of agricultural commercialization revealed by the COMPS and CIMPS indicators. Households with at least a crop output market participation share (COMPS) and crop input market participation share (CIMPS) proportion of $40 \%$ were regarded as the commercialized whilst households that had CIMPS and COMPS values less than $40 \%$ were regarded as non-commercialized households. The choice of $40 \%$ was made so as to come out with a clear cut and separation of farmers who are into agricultural commercialization and those who are not. The choice of this figure follows the literature indicating that agricultural commercialization for field crops is averagely low in Africa and many farmers sell output that is less than half of what they produce (Aryemo et al., 2019; Rubhara and Mudhara, 2019). This implies that farmers selling more than $40 \%$ of their gross crop value are commercialized and also farmers who use purchased gross input value above $40 \%$ are commercialized. The farmers meeting both the conditions of both COMPS and CIMPS values greater than the $40 \%$ were therefore regarded as commercialized in this study.

Since the study aims at measuring the impact of agricultural commercialization on household food security then measuring household food security was required. Many indicators can be used to measure household food security that include household dietary diversity score coping strategies index (CSI) and other many indicators that will be narrated in the literature review. This paper measures household food security using a modified food consumption score (MFCS) which builds upon the Food Consumption Score (FCS) which measures the food access component of household food security. This study captured the weekly average household consumption frequencies of food in 
the eight food groups. This information was used to compute the food consumption scores then aggregated to form the modified food consumption score (MFCS). The FCS has a standard questionnaire that is used to collect data. In this study, the FCS questionnaire was modified to reflect the household food security status for the whole year. Food consumption scores for three different seasons of the year were collected stretching from June 2018 up to May 2019. The three seasons have different implications on household food availability and access characteristics particularly to the target farming population in Zhombe North Rural District. The first period stretching from June to September is mostly characterised with moderate food availability since farmers would have harvested their crops. On the other hand, this period can be associated with high food shortages especially when the immediate farming season produced low yields.

The second period stretching from October to January can be regarded as the busiest season for farmers packed with planting and weeding activities. Usually, this period is the lean season when many households experience food shortages due to depleted food stocks. Again, due to the intensity of the agricultural activities in this season, the frequency of meals can be reduced not only as a result of food shortages but also as a failure to get enough time for food preparation. Many households can spend the whole day in fields drinking mahewu (a homemade, non-alcoholic drink made from slightly fermented maize meal porridge).

The third period stretches from February to May and when there are normal rains, this period is usually characterised with plenty of fresh food such as green mealies, squashes, pumpkin leaves and a wide range of traditional edible plant leaves used as a relish. When there is drought, however, farmers may not have plenty of food in this season.

Literature shows scanty and inconclusive scientific evidence on that agricultural commercialization improves food security and nutritional outcomes with the direction of the effects ranging from negative, neutral to slight positive which calls for more research to clarify the relationships between the two (Carletto et al., 2017; Linderhof et al., 2019; Radchenko and Corral, 2018). The critics of commercialization through growing of cash crops maintain that if countries promote the production of the cash crops and not use the obtained money from exports to buy staple food then the country experience high prices of food on a national level that has detrimental effects on the poor people. Agricultural commercialization through the production of non-food cash crops reduces land that is available for farming households to grow food crops like maize, groundnuts, millet, sorghum, round nuts, sweet potatoes, etc.

A study that was done in Western Kenya to find the impact of agricultural commercialization on food security used the generalised propensity score method that controlled for the structural confounding problem and revealed that commercialization improves food security and dietary quality (Ogutu et al., 2017). Another study that was done using Malawian data provided some light on the controversial matter of the effect of agricultural commercialization on household food security. It applied a model with essential heterogeneity and revealed that cash cropping benefits or hurts household food security at different levels of the farming population (Radchenko and Corral, 2018). Literature indicates that economic and social conditions vary across regions and countries so it would be necessary to conduct a scientific inquiry for policy guidance on the impact or effects of agricultural commercialization on nutrition or food security. Farmers who grow more non-food crops, compared to food crops experience a challenge from high food prices volatility hence hurting their welfare.

The promotion of commercialization through high-value crops may fail to induce the required income growth especially when the staple crop yields are low (Dzanku, 2015). Promotion of growth of the food crops yield and the commercialization of smallholder farmers through food crops enhances solving of poverty and food insecurity. Another argument is that the relationship between agricultural commercialization and food security is complex given heterogeneous households' response and the non-linear elasticity of nutritional outcomes 
(Carletto et al., 2017). Few studies have applied models that address structural confounding in estimating the effects of agricultural commercialization which can give biased estimates (Heckman et al., 1998; Geoffrey Muricho, 2015).

\section{Materials and methods}

\section{Study area}

Zhombe North Rural District is located 155 kilometres North West of the Midlands provincial capital of Gweru taking approximately a three-hour bus ride from Gweru. The area is $70 \mathrm{~km}$ southwest of Kadoma town and $104 \mathrm{~km}$ northwest of Kwekwe town. This area is part of the Midlands province under the Zibagwe Rural District Council forming part of the rural Kwekwe. Zhombe North Rural District constitutes 11 wards out of the 33 wards under the Zibagwe rural district council. The area lies at $18.667^{\circ} \mathrm{S}$ and $29.349^{\circ} \mathrm{E}$ latitudes of the subtropics. It is in the natural farming region 3 and experience severe mid-season dry spells receiving an average of $600-650 \mathrm{~mm}$ of rainfall per year (Hanyani-Mlambo et al., 2000). The climatic condition in Zhombe North Rural District is hot semi-arid or steppe climate as the area receives precipitation below the area's potential evapotranspiration but cannot be as low as in desert climate (Mugandani et al., 2012). Major livelihood activities in this area include agriculture and mining.

The study focussed on rain-fed smallholder farmer households in the Zhombe North Rural District with the household as the unit of analysis. Zhombe North Rural District has 3 wards which are ward 6 (also known as Mabura/ Columbina), ward 7 (also known as Sidhakeni) and ward 8 (also known as Empress Mine). The Midlands province in which Zhombe North Rural District is located has serious food insecurity challenges as revealed by the famine and early warning system network (FEWS NET, 2017). The inclusion of the crops in the study was limited to rain-fed food and non-food crops only. The food crops were limited to cereal and legume crops which were maize, sorghum, groundnuts, round nuts and cowpeas. The field-grown cash crop in the study area is cotton.
The reason for choosing the rain-fed cropping farmers was that the largest proportion of people experiencing food insecurity in the world are the rural smallholder farmers who depend on rainfed agriculture. It would be important to investigate ways through which food security for these households can be enhanced (FAO et al., 2018; Shenggen et al., 2019). This study used the 2017/2018 season cross-sectional data in Zhombe North Rural District collected from the ward numbers 6, 7 and 8 . The survey captured qualitative and quantitative data on household socio-economic characteristics, farming activities as well as the food security aspect of the households. Data was collected from 165 households in a two-stage sampling method.

\section{Analytical framework}

The propensity score matching method was used to measure the impact of agricultural commercialization on household food security. This method was developed by Rosenbaum and Rubin in 1983 to simultaneously balance multiple observed covariates between the treated and untreated groups (Rosenbaum and Rubin, 1983). This method has gained popularity both in the empirical and theoretical circles and can be used when there is no baseline data. PSM is suitable when the data is cross-sectional, presence of a bigger control group and if it is possible to establish common support to match the treated and the control respondents to measure the impact of treatment basing on the propensity scores of being treated (Rosenbaum and Rubin, 1983). Matching basing on a large number of covariates may result in dimensionality problems and this can be solved by matching only using propensity scores which is a single variable created in PSM (Rosenbaum and Rubin, 1983). The outcome of the commercialized households (treatment group) is compared to the outcome of non-commercialized households (control group) with similar propensity scores to obtain treatment effects. The important steps that were followed in performing propensity score matching are identified as; selection of covariates, estimating propensity scores, restricting analysis to the region of common support, checking the balancing property and finally estimating the average treatment effect of the treated group. 


\section{Selection of covariates}

The set of background covariates used in this study are shown in Table 1 . These were the factors identified as influencing agricultural commercialisation and the factors were fixed in the households before treatment. The covariates were correlated with household food security and were imbalanced across the commercialized and non-commercialized households. The covariates were identified from the literature search and these were household head age, household size, distance from the water source, land size, distance from the market, distance from the main road and level of education. A study that was done in Mashonaland Central Province of Zimbabwe applying a Tobit regression model indicated that age had a significant negative influence on agricultural commercialisation (Rubhara and Mudhara, 2019). As the family head grows older, the level of participation in farm markets tends to decline which may be associated with reduced power as a person grows older.

Table 1: Factors affecting agricultural commercialization used as covariates in PSM

\begin{tabular}{lll}
\hline Description of variable & Measurement & Expected Relationship \\
\hline Household head age & Number of years & - \\
Household size & Number of people & + \\
Distance from safe water source & Kilometres & - \\
Land size & Hectares & + \\
Distance from market & Kilometres & - \\
Distance from the main road & Kilometres & - \\
Primary level of education and below & $1=$ Yes, 0=Otherwise & + \\
Secondary level of education & $1=$ Yes, 0=Otherwise & - \\
Tertiary level of education & $1=$ Yes, 0=Otherwise & \\
\hline
\end{tabular}

Another study that was done in Ethiopia using a Tobit regression model indicated that land size and family size positively affected commercialisation whilst old age negatively affected commercialisation (Bekele and Alemu, 2015). Other studies that were done in South Africa and Zimbabwe also concur with the result that land size positively affects commercialisation (Makhura et al., 2001; Mussema et al., 2013; Siziba et al., 2011). The authors indicated that as land size increases, farmers are likely to produce more surplus that is then channelled to the markets. Evidence shows that age is negatively associated with commercialisation with younger farmers more likely to participate in agricultural commercialisation than older farmers (Bekele and Alemu, 2015; Mussema et al., 2013).

Studies that were done in Kenya and Ethiopia using ordered Tobit model revealed that age was negatively associated with market participation
(Bellemare and Barrett, 2006). Distance from the market was found to negatively affect commercialisation and farmers that were close to feeder roads and markets had higher commercialisation indices (Alene et al., 2008; Mussema et al., 2013; Siziba et al., 2011).

A study that was done in Rwanda using the Double-hurdle model to find the factors affecting market participation in bean farmers revealed that land size and education level had positive significant effects on the commercialisation (Ingabire et al., 2017). The land size was also found to have a positive significant influence on agricultural commercialisation on a study done in Bangladesh using a Probit regression model (Gani and Hossain, 2015). The same study also found household labour or household size to have a positive significant effect on agricultural commercialisation. 


\section{Estimating the propensity scores}

After the identification of covariates, propensity scores have to be estimated. This step is required because the true propensity scores are unknown, hence, they need to be estimated. There are different models through which propensity scores can be estimated and these include Logit model, Probit model, discriminant analysis, mahalanobis distance analysis, among others. Researchers decided not to use mahalanobis distance analysis since it uses exact matching and cannot work well when covariates are highly dimensional and not normally distributed. The Logit model was used because it matches well even if the covariates are not normally

\begin{tabular}{lll} 
even if the covariates are not & normally \\
\hline Variable & Coef. (S.E) & z-value \\
\hline Household head age & $-.037088^{*}(.019)$ & -1.91 \\
Land size & $1.414239^{* * *}(.29)$ & 4.91 \\
Primary level of education and below & $.3844487(1.30)$ & 0.29 \\
Secondary level & $.2399357(1.29)$ & 0.19 \\
Tertiary level & $-.4856159(1.57)$ & -0.31 \\
Distance from the market & $.1919532^{* * *}(.06)$ & 3.36 \\
Distance from the main road & $-.127879^{* * *}(.05)$ & -2.57 \\
Household size & $-.1312209(.09)$ & -1.53 \\
Distance from the safe water source & $.3526453(.35)$ & 1.00 \\
Constant & $-3.109358^{*}(1.9)$ & -1.64
\end{tabular}

distributed. The computer package used was STATA 14. Propensity scores show the probabilities of being commercialized. The treatment variable was agricultural commercialization which would take a value of 1 if the households are commercialized and zero for non-commercialized households. The propensity scores are shown in Table 2 . The mean propensity score was $31.5 \%$ and the McFadden Pseudo $\mathrm{R}^{2}$ value was 0.31 . The Hosmer Lemeshow test indicated that the model was well fitted.

Table 2 Estimating propensity scores using the Logit model

\section{Restricting the analysis to the region of common support using kernel and stratification matching algorithms}

In this paper commercialized households were matched with the non-commercialized households with similar propensity score values. Matching was done only on the region of common support determined by the propensity scores of the treated and untreated cases. The matching methods that were used were the stratification and the kernel matching. The kernel matching method was chosen because it could discard any cases not matched hence retaining only suitable cases for matching. The kernel matching method has a strength in that it can only match cases that fall in a stipulated radius of propensity scores and discard cases that do not fall in the propensity score radius.

There were 52 commercialized households and 113 non-commercialized households in the sample. The stratification method matched 48 treated cases to 76 untreated cases whilst the kernel matching method matched 47 treated cases to 76 untreated cases. The region of common support is the overlap of the propensity scores between treated and untreated cases. This means that in the kernel matching method, 5 treated cases and 37 untreated cases were discarded whilst 4 treated cases and 37 untreated cases were discarded for the stratification matching method. The optimal number of blocks were 5 . The common support condition is shown in figure 1 indicating that treated cases and untreated cases were successfully matched.

\section{Checking the balancing property}

The propensity score matching method was chosen to address the structural confounding problem and ensure that cases with similar observable characteristics are compared. The balancing property of the propensity scores was 
necessary to ensure that the estimation of the average treatment effects on the treated (ATT) results are reliable and valid (Vyas and Heise, 2014). The tests that were used included the t-test, percentage bias, Rubin's B, Rubin's $\mathrm{R}$ and the Pseudo $R^{2}$. Table 3 indicates the t-test and percentage bias results for the covariates before and after matching the cases.
Table 3 indicates that the balancing property was met as the $\mathrm{t}$-test results show that the differences in the variable means between the commercialized and non-commercialized households were statistically insignificant after matching. Also, the standardized percentage bias between the sample means of the commercialized and the non-commercialized households was able to be reduced to 4.9 which falls in the

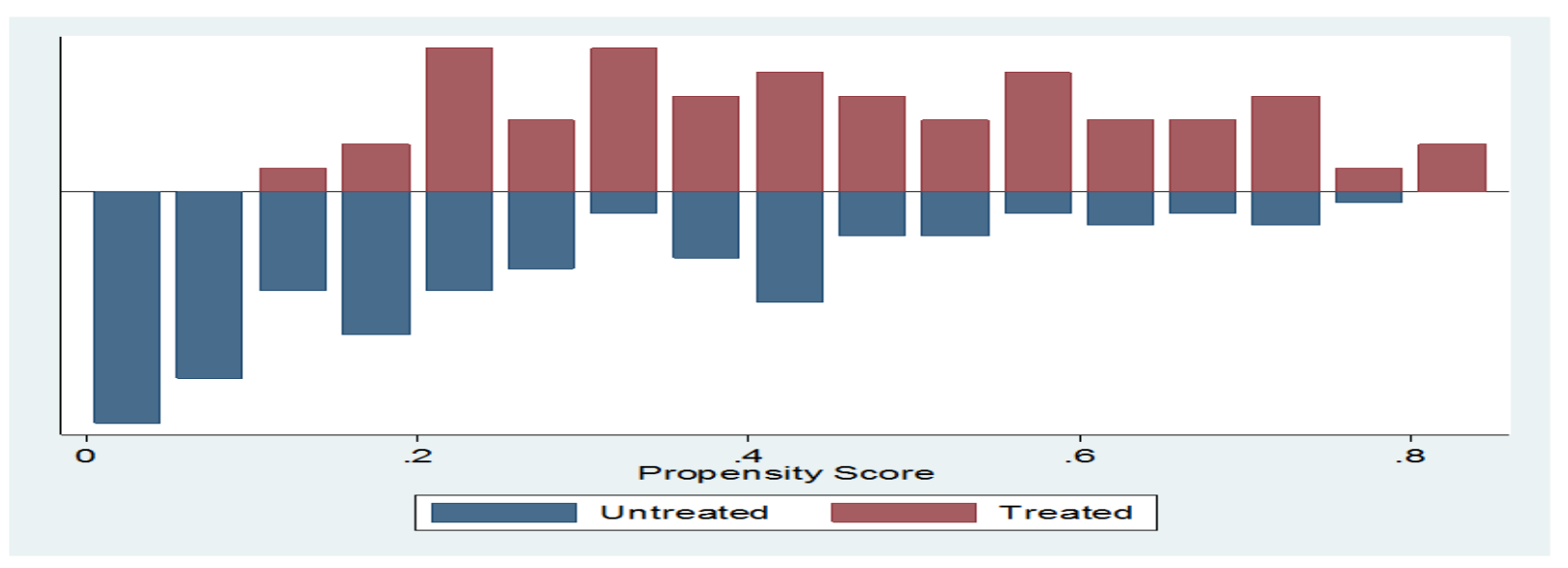

Figure 1. Common Support in Zhombe North Rural District

range of the allowed mean bias levels stated in the literature. The mean bias of a valid model should fall below $5 \%$ for the balancing property to be satisfied.

Table 3: Balancing tests of propensity scores and covariates before and after matching $(n=165)$

\begin{tabular}{|c|c|c|c|c|c|c|}
\hline Variable & Sample & Treated & Control & \%bias & $\mathbf{T}$ & $p>t$ \\
\hline \multirow[t]{2}{*}{ Household head age } & Unmatched & 47.69 & 52.49 & & & \\
\hline & Matched & 47.162 & 47.973 & -6.2 & -0.29 & 0.770 \\
\hline \multirow[t]{2}{*}{ Land size } & Unmatched & 2.55 & 1.43 & & & \\
\hline & Matched & 2.2431 & 2.2322 & 1.2 & 0.05 & 0.959 \\
\hline \multirow{2}{*}{$\begin{array}{l}\text { Primary level of } \\
\text { education and below } \\
\text { (yes }=1 ; 0=\text { otherwise) }\end{array}$} & Unmatched & 0.13 & 0.22 & & & \\
\hline & Matched & .18919 & .18919 & 0.0 & 0.00 & 1.000 \\
\hline $\begin{array}{l}\text { Secondary level (yes=1; } \\
0=\text { otherwise) }\end{array}$ & $\begin{array}{l}\text { Unmatched } \\
\text { Matched }\end{array}$ & $\begin{array}{l}0.75 \\
.72973\end{array}$ & $\begin{array}{l}0.71 \\
.7027\end{array}$ & 6.0 & 0.25 & 0.800 \\
\hline \multirow{2}{*}{$\begin{array}{l}\text { Tertiary level } \quad \text { (yes=1; } \\
0=\text { otherwise) }\end{array}$} & Unmatched & 0.06 & 0.055 & & & \\
\hline & Matched & .05405 & .05405 & 0.0 & 0.00 & 1.000 \\
\hline \multirow{2}{*}{$\begin{array}{l}\text { Distance from the } \\
\text { market }\end{array}$} & Unmatched & 16.52 & 13.36 & & & \\
\hline & Matched & 15.432 & 15.676 & -4.9 & -0.22 & 0.823 \\
\hline \multirow{2}{*}{$\begin{array}{l}\text { Distance from the main } \\
\text { road }\end{array}$} & Unmatched & 9.77 & 9.33 & & & \\
\hline & Matched & 10.054 & 10.486 & -8.1 & -0.31 & 0.758 \\
\hline \multirow[t]{2}{*}{ Household size } & Unmatched & 6.67 & 5.35 & & & \\
\hline & Matched & 6.4054 & 5.973 & 14.2 & 0.67 & 0.507 \\
\hline \multirow{2}{*}{$\begin{array}{l}\text { Distance from the safe } \\
\text { water source }\end{array}$} & Unmatched & 0.98 & 0.86 & & & \\
\hline & Matched & .93784 & .91892 & 3.3 & 0.15 & 0.883 \\
\hline
\end{tabular}


Table 4 shows the results of the Pseudo $\mathrm{R}^{2}$, Rubin's B and Rubin's R. Literature indicates that the Pseudo $R^{2}$ shows the probability of participating and if the values are compared before and after matching it can be noted that before matching it was 0.31 and 0.01 after matching. This value should be fairly low after matching (Rosenbaum and Rubin, 1983). The value of 0.01 after matching indicates that the matching was valid and relevant. Rubin's B test is the absolute standardized difference between the means of the linear index between the treated and untreated cases and this theoretically recommended to be less than 25 for the sufficiently balanced samples (Rosenbaum and Rubin, 1983). In this study, the value was 23.1 indicating that the sample covariates were sufficiently balanced. The recommended Rubin's $R$ values should fall between 0.5 and 2 according to literature. The result in Table 4 was 0.69 hence concluding that the balancing property was satisfied.

Table 4. Balancing tests of the covariates (Pseudo R2, Rubin's B and Rubin's R)

\begin{tabular}{lccccccc}
\hline PS R2 & LR Chi2 & p>chi2 & MeanBias & MedBias & B & R & 8Var \\
\hline 0.010 & 1.03 & 0.999 & 4.9 & 4.9 & 23.1 & 0.69 & 17 \\
\hline
\end{tabular}

Estimating the average treatment effect by matching based on propensity scores

After estimating the propensity scores and matching them using a selected matching algorithm, the impact of agricultural commercialization on household food security was estimated using the average treatment effects on the treated (ATT). The ATT PSM estimator is the most recommended though many researchers estimate the average treatment effect (ATE). The PSM estimator of ATT is specified as;

$T_{A T T}^{P S M}=\frac{E_{p\left(X_{i}\right)}}{D_{i}}=1\left\{E\left[\frac{Y_{i}(1)}{D_{i}}=1, P\left(X_{i}\right)\right]-E\left[\frac{Y_{i}(0)}{D_{i}}=0, P\left(X_{i}\right)\right]\right\}$ (Cameron and Trivedi, 2005).

To measure the impact of agricultural commercialization on household food security, comparisons were made between commercialized and non-commercialized households. Household food security was the outcome variable in the model, measured using modified food consumption scores (MFCS). The MFCS was computed from the estimated household food consumption scores as narrated in the introduction section of this paper. The treatment was agricultural commercialization whilst non-commercialized households were the control group. Households that had a COMPS and a CIMPS value equating to or above 0.4 were considered as the commercialized households and vice versa is true. This was done because agricultural commercialization not only includes the sale of crops but also input market engagement. Commercialized households were matched with non-commercialized households based on propensity scores of an observed set of covariates to estimate the impact of agricultural commercialization on household food security.

\section{Results}

The results from the Logit model indicates that factors such as land size and distance from the market have a positive influence on agricultural commercialization whilst household head age and distance from the main road had negative influence on agricultural commercialization. The land size had a positive influence on agricultural commercialisation at a $1 \%$ level of significance $(p>0.01)$. An increase in the land size by 1 hectare holding all other factors constant, would result in an instantaneous increase in the average input and output market participation value by 1.41 . An increase in the distance from the market by 1 
$\mathrm{km}$ holding all other things constant would result in the increase in the average input and output market participation value by 0.19 . This result is controversial to the usual phenomena that is normally associated with market participation since normally the relationship is negative. This case might be a sign that there is malfunctioning of local markets in the study area.

Household head age negatively affected agricultural commercialisation at a $10 \%$ level of significance $(p<0.1)$. An increase in the age of the household head by 1 year would result in an instantaneous decline of the input and crop output market participation value by 0.037 . Distance from the main road negatively influenced agricultural commercialization at a $1 \%$ level of significance. An increase in distance from the main road by $1 \mathrm{~km}$ would lead to a decline in the input and output market participation by 0.13 . The overall interaction of the factors had a positive influence on agricultural commercialisation as indicated by the positive significance of the constant at $10 \%$ Table 5. Treatment effects of agricultural commercialization on household food security $(n=165)$

\begin{tabular}{|c|c|c|c|c|c|c|c|}
\hline Variable & $\begin{array}{l}\text { Matching } \\
\text { method }\end{array}$ & Sample & Commercialized & $\begin{array}{l}\text { Non- } \\
\text { commercialized }\end{array}$ & ATT & S. E & $\begin{array}{l}\text { T. } \\
\text { Stat }\end{array}$ \\
\hline Modified & Kernel & Matched & 47 & 76 & 5.089 & 1.848 & 2.754 \\
\hline $\begin{array}{l}\text { food } \\
\text { consumption } \\
\text { score } \\
\text { (MFCS) }\end{array}$ & Stratification & Matched & 48 & 76 & 5.563 & 1.852 & 3.004 \\
\hline
\end{tabular}

results show that commercialized households had 5.563 more modified food consumption scores compared to the non-commercialized households. This means that agricultural commercialization improved household food security for commercialized households by 5.563 modified food consumption scores compared to the non-commercialized households. The impact of agricultural commercialization on household food security ranged from 5.089 to 5.563 modified food consumption scores. The results were significant at $95 \%$ level of significance. This concludes that agricultural commercialization improved household food security access component of the commercialized households. level. The interaction of the factors would increase the input and output market participation value by 3.1 .

The impact of agricultural commercialization on household food security was estimated using the average treatment effects on the treated (ATT). The ATT was estimated using two different matching estimators which are the kernel matching and the stratification matching methods. Table 5 shows the estimated results of the ATT after matching using different matching methods. The average treatment effects of agricultural commercialization on household food security were 5.089 modified food consumption scores using the kernel matching method.

This result implies that commercialized households were expected to have 5.089 more modified food consumption scores compared to the non-commercialized households. The stratification matching method 
was the modified food consumption score explained in the introduction of this paper. The commercialized and non-commercialized households had significant differences in the covariates which also influenced the commercialization.

The Logit model revealed that land size and distance from the market had significant positive influence on agricultural commercialization whilst household head age and distance from the main road had significant negative influence on agricultural commercialization. The impact of agricultural commercialization on household food security was found to be positive hence the way through which the household food security can be enhanced is through the promotion of factors affecting agricultural commercialization.

The land size had a positive influence on agricultural commercialisation. This result was also found by other scholars who revealed the positive influence of land size on agricultural commercialisation (Gani and Hossain, 2015; Makhura et al., 2001; Mussema et al., 2013; Siziba et al., 2011). The scholars highlighted that land proves to be a very useful asset to achieve commercialisation as it enables households to shift from subsistence farming towards commercial farming as through producing more surplus that can be channeled to markets. Again, the households with larger land portions realize the economies of scale and they can become more profitable than households with very small land portions (Melo and Tsikata, 2014).

Household head age negatively affected agricultural commercialisation. This may be because younger household heads are still energetic and can have higher labour productivity than the older household heads that translates into more output surplus that can be sold on the market. Given that cotton which is the highly commercialized crop in Zhombe North is labour intensive in activities such as weeding, spraying and harvesting, younger household heads have more energy to grow the laborintensive crop. Younger household heads also have more cash requirements for school fees and other demands such as asset accumulation hence they become engaged in agricultural commercialisation than older household heads to increase their income. Other researchers revealed the same negative effect of household head age on agricultural commercialisation (Bekele and Alemu, 2015; Bellemare and Barrett, 2006; Mussema et al., 2013).

Distance from the market positively affected agricultural commercialization and this is contradictory to the normal scenario whereby an increase in distance from the farmer's household to the market then the market participation would decline. This result may imply the nonfunctionality of the local markets in Zhombe North Rural District. Distance from the main road is the one that is negatively affecting agricultural commercialization. An increase in the distance from the main road is leading to the decline in agricultural commercialization. This result implies the important role played by road networks in promoting agricultural commercialization in smallholder farmers in the Zhombe North Rural District.

\section{Conclusion}

In this study, it can be concluded that agricultural commercialization has a positive impact on household food security. The study, therefore, recommends policies that would promote agricultural commercialisation that in turn improve household food security. The researcher proposes the ways of promoting agricultural commercialisation through leveraging on the factors affecting agricultural commercialization. It can be concluded that land size and distance from the market have positive influence on agricultural commercialization whilst household head age and distance from the road have negative influence on agricultural commercialization. Since the study revealed that agricultural commercialization has a positive impact on household food security then the promotion of agricultural commercialization in turn improves the household food security.

The policy recommendations that were therefore made by the researchers are include restructuring of the land size holdings so as to ensure that farmers secure enough land to produce crops for consumption and have surplus to channel to the markets, targeting young smallholder farmers in the agricultural commercialisation programmes 
since they have energy to cultivate land and produce crops compared to the older farmers and the government has to ensure that it creates many feeder roads in the rural areas so that smallholder farmers have the opportunity to easily transport crops to markets. Last but not least, policy makers need to enhance the availability of inputs such as improved seeds and fertilizers to farmers as well as setting of minimum farm wages so that production is enhanced to increase agricultural commercialization.

\section{References}

Alene, A. D., Manyong, V. M., Omanya, G., Mignouna, H. D., Bokanga, M., and Odhiambo, G. (2008). Smallholder market participation under transactions costs: maize supply and fertilizer demand in Kenya. Food Policy, 33(4), 318-328.

Aryemo, I. P., Akite, I., Kule, E. K., Kugonza, D. R., Okot, M. W., and Mugonola, B. (2019). Drivers of commercialization: A case of indigenous chicken production in northern Uganda. African Journal of Science, Technology, Innovation and Development, $\quad 0(0)$, 1-10. https://doi.org/10.1080/20421338.2019. 1573957

Bekele, A., and Alemu, D. (2015). Farm-level determinants of output commercialization: In haricot bean based farming systems. Ethiopian Journal of Agricultural Sciences, 25(1), 61-69.

Bellemare, M. F., and Barrett, C. B. (2006). An Ordered Tobit Model of market participation: Evidence from Kenya and Ethiopia. American Journal of Agricultural Economics, 88(20), 324-337.

Cameron, A. C., and Trivedi, P. K. (2005). Microeconometrics: Methods and applications. Cambridge University Press.

Carletto, C., Corral, P., and Guelfi, A. (2017). Agricultural commercialization and nutrition revisited: Empirical evidence from three African countries. Food Policy, 67, 106-118. https://doi.org/10.1016/j.foodpol.2016. 09.020

\section{Acknowledgements}

Researchers would like to thank the African Economic Research Consortium (AERC) for funding this research through the Collaborative Masters in Agricultural and Applied Economics (CMAAE) program.

Chopak, J. C. (1988). Family Food Security Strategies in Low Rainfall Areas. In D. G. Mudimu and R. H. Bernstern (Eds.), Household and National Food security in Southern Africa. University of Zimbabwe.

Diao, X., Hazell, P., Resnick, D., and Thurlow, J. (2006). The role of agriculture in development: Implications for subSaharan Africa. International Food Policy Research Institute.

Dzanku, F. M. (2015). Household-specific food price differentials and high-value crop production in rural Ghana. Food Policy, $57,73-82$.

FAO, IFAD, UNICEF, WFP, W. (2018). The state of Food Security and Nutrition in the World 2018. Building Climate Resilience for Food Security and Nutrition.

FEWS NET. (2017). Zimbabwe Food Security Status. http//www.FEWSNET.com

Gani, O., and Hossain, E. (2015). Market participation decision of smallholder farmers and its determinants in Bangladesh. Economics of Agriculture, 62(1), 163-179. https://doi.org/10.5937/ekopolj150116 $3 g$

Government of Zimbabwe. (2018). National agriculture policy framework (20182030): First Draft.

Hall, C., Dawson, T. P., Macdiarmid, J. I., Matthews, R. B., and Smith, P. (2017). The impact of population growth and climate change on food security in Africa: Looking ahead to 2050. International Journal of Agricultural Sustainability, 15(2), 124-135. https://doi.org/10.1080/14735903.2017. 1293929 
Hanyani-Mlambo, B. T., Sibanda, S., and Rukuni, M. (2000). Farming systems in Zimbabwe's smallholder agricultural sector: the case of Gokwe South District (2/2000; AEE Working Paper). https://opendocs.ids.ac.uk/opendocs/ bitstream/handle/123456789/7046/Ha nyani-Mlambo BT\%2CSibanda\%2CS and Rukuni\%2CM DAEE Working Paper AEE 2 $\% 282000 \% 29$.pdf? sequence $=1$ andisAllo wed $=\mathrm{y}$

Heckman, J. J., Ichimura, H., and Todd, P. (1998). Matching as an econometric evaluation estimator. Review of Economic Studies, 65, 261-294.

Ingabire, C., Mshenga, M. P., Langat, K., Bigler, C., Musoni, A., Butare, L., and Birachi, E. (2017). Towards commercial agriculture in Rwanda: Understanding the determinants of market participation among smallholder bean farmers. African Journal of Food, Agriculture, Nutrition and Development, 17(4), 12492-12508.

https://doi.org/10.18697/ajfand.80.168 25

Jaleta, M., Gebremedhin, B., and Hoekstra, D. (2009). Smallholder commercialization: processes, determinants and impact. (No. 18; ILRI Discussion Paper). ILRI (international Livestock Research Institute).

Jayne, T. S., Chisvo, M., Rukuni, M., and Masanganise, P. (2006). Zimbabwe's food insecurity paradox: Hunger amid potential. In Zimbabwe's agricultural revolution revisited (pp. 525-541). University of Zimbabwe.

Jayne, T. S., Haggblade, S., and Minot, N. and Shahid, R. (2011). Agricultural Commercialization, Rural Transformation and Poverty Reduction: What have we Learned about How to Achieve This? International Multidisciplinary Research Journal, 5(4).

Jones, A. D., Shrinivas, A., and Bezner-Kerr, R. (2014). Farm production diversity is associated with greater household dietary diversity in Malawi: Findings from nationally representative data. Food Policy, 46, 1-12. https://doi.org/10.1016/j.foodpol.2014. 02.001

Linderhof, V., Janssen, V., and Achterbosch, T. (2019). Does Agricultural Commercialization Affect Food Security: The Case of Crop-Producing Households in the Regions of Post-Reform Vietnam? Sustainability, 11(5), 1263. https://doi.org/10.3390/su11051263

Makhura, M. N., Kristen, J., and Delgado, C. (2001). Transaction costs and small holder participation in the maize market in the northern province of South Africa. Seventh Eastern and Southern Africa Regional Maize Conference: 11-15 February 2001, 463-467.

Mapfumo, A. (2015). An Econometric Analysis of the Relationship between Agricultural Production and Economic Growth in Zimbabwe. Russian Journal of Agricultural and Socio-Economical Sciences, 11(23), 11-15.

Maxwell, D., Coates, J., and Vaitla, B. (2014). How do indicators of household food insecurity measure up? An empirical comparison from Ethiopia. Food Policy, 47, 107-116.

Mugandani, R., Wuta, W., Makarau, A., and Chipindu, B. (2012). Re-Classification of Agro-Ecological regions of Zimbabwe in conformity with climate variability and change. African Crop Science Journal, 20(s2), 361-369. https://doi.org/10.4314/acsj.v20i2.

Muricho, G., Kulundu, D., and Sule, F. (2018). Impact Assessment of Agricultural Commercialization on Food Security Among Smallholder Farmers in Kenya: An Application of Correlated Random Effects. International Conference of Agricultural Economists. https://ageconsearch.umn.edu/record/ 277325

Muricho, Geoffrey. (2015). Determinants of agricultural commercialisation and its impacts on welfare among smallholder farmers in Kenya. University of Nairobi.

Mussema, R., Kassa, B., Alemu, D., and Rashid, S. (2013). Analysis of the Determinants of Small-Scale Farmers' Grain Market Participations in Ethiopia: The 
Contribution of Transaction Costs. J. Agric. Sci, 23, 75-94.

Ogutu, S. O., Gödecke, T., and Qaim, M. (2017). Agricultural Commercialization and Nutrition in Smallholder Farm Households (No. 97). Article 97. http://www.unigoettingen.de/de/213486.html

Radchenko, N., and Corral, P. (2018). Agricultural Commercialisation and Food Security in Rural Economies: Malawian Experience. The Journal of Development Studies, 54(2), 256-270. https://doi.org/10.1080/00220388.2017. 1283014

Rosenbaum, P. R., and Rubin, D. B. (1983). The central role of the propensity score in observational studies for causal effects. Biometrika, 70, 41-55.

Rubhara, T., and Mudhara, M. (2019). Commercialization and its determinants among smallholder farmers in Zimbabwe. A case of Shamva District, Mashonaland Central Province. African Journal of Science, Technology, Innovation and Development, 0(0), 1-8. https://doi.org/10.1080/20421338.2019. 1571150

Rukuni, M. (2002). Africa: Addressing growing threats to food security. Journal of Nutrition, 3443-3448. http://www.scopus.com/inward/recor d.url?eid=2-s2.0-

0036845208and partnerID $=40$ andmd $5=9 \mathrm{f}$ 32009742b1a160a483c17d9519cd5b

Shenggen, F., Arndt, C., Malapit, H., MeinzenDick, R., Resnick, D., and Thurlow, J. (2019). Global Food Policy Report. http://www.ifpri.org

Siziba, S., Nyikahadzoi, K., Diagne, A., O., F. A., and A, A. A. (2011). Determinants of cereal market participation by subSaharan Africa smallholder farmer. Learning Publics Journal of Agriculture and Environmental Studies, 2(1), 180193.
Strasberg, P., Jayne, T., Yamano, T., Nyoro, J., Karanja, D., and Strauss, J. (1999). Effects of Agricultural Commercialization on Food Crop Input Use and Productivity in Kenya. In Michigan State University, Department of Agricultural, Food, and Resource Economics, Food Security International Development Working Papers.

Timmer, C. P. (2005). Agriculture and Pro-Poor Growth: An Asian Perspective (No. 62; Working Paper, Issue 63).

von Braun, J., and Kennedy, E. (1994). Agricultural Commercialization, Economic Development, and Nutrition.

Vyas, S., and Heise, L. (2014). Using Propensity Score Matching to Estimate an "Unbiased Effect-Size" Between Women's Employment and Partner Violence in Tanzania. Journal of Interpersonal Violence, 29(16), 29712990.

https://doi.org/10.1177/0886260514527 823

WFP. (2008). Food consumption analysis: Calculation and use of the food consumption score in food security analysis. United Nations World Food Programme.

WFP. (2015). Consolidated Approach to Reporting Indicators of Food Security (CARI) (Issue November).

Wiggins, S. (2004). Food security options in Zimbabwe: multiple threats, multiple opportunities? In Country Food Security Options Paper (No. 5; Country Food Security Options Paper, Issue 5). www.odi.org.uk/food-security-forum

World Bank. (2019). Zimbabwe data. http://data.worldbank.org/country/zi mbabwe

ZIMSTAT. (2017). Inter-censal demographic survey (p. 192). Zimbabwe National Statistics Agency Publications.

ZimVAC. (2018). Households and community survey. Food and Nutrition Council Publications. http://www.fnc.org.zw 